\title{
Pattern of ovarian steroid secretion during ovulation of in- vitro perfused rat ovaries varies with method of sampling
}

\author{
Y. Higuchi and L. L. Espey \\ Department of Biology, Trinity University, San Antonio, Texas 78284, USA
}

\begin{abstract}
Summary. Wistar rats were primed at 25 days of age with 20 i.u. PMSG s.c., followed $48 \mathrm{~h}$ later with $100 \mathrm{ng} \mathrm{LH} / \mathrm{ml}$ to induce the ovulatory process in vitro. Assays for progesterone, oestradiol, and testosterone were performed on samples taken at fixed intervals of $0,1,2,4,8$ and $12 \mathrm{~h}$ after $\mathrm{LH}$ administration. The results show that, while there was some degree of correlation in the concentrations of progesterone between the ovarian extract and perfusate, there were very large differences in the measurable amounts of testosterone and oestrogen in the fluid samples and ovarian homogenates. Therefore, taking samples from the perfusate may not provide a good assessment of the steroidogenic activity in the ovary.
\end{abstract}

Keyw'ords: ovary; ovulation; progesterone; testosterone; oestradiol; in-vitro perfusion

\section{Introduction}

During the past decade, the in-vitro perfusion method has been used more and more to study the biochemical events of ovulation in rats and rabbits (Wallach et al., 1978; Janson et al., 1982; LeMaire et al., 1982; Holmes et al., 1983, 1986; Koos et al., 1984; Koos \& LeMaire, 1985; Shaykh et al., 1985; Schmidt et al., 1986; Yoshimura et al., 1986, 1987, 1988; Brännström et al., 1987a, b). In virtually all of these studies, ovarian steroids and/or prostaglandins (PG) were analysed by assaying samples of the circulating perfusion medium. In only one instance (Koos et al., 1983) was an effort made to compare the patterns of change in any of these agents in the perfusion fluid with those in the ovary: PGE and PGF were assayed in the perfusion fluid and in ethanol extracts of the follicular fluid of perfused ovaries. The results showed a "lack of relationship between PG concentrations measured in the medium and in the follicular fluid". These findings suggest that there could also be a poor correlation in the measurable amounts of steroids in the perfusion fluid and in the ovary. In fact, when one compares measurements in vitro and in vivo, the "steroid profiles in the perfusion medium profoundly differ from those observed in vivo" (Thibault \& Lavasseur, 1988).

In the present study, progesterone, testosterone, and oestradiol concentrations in the perfusion fluid from rat ovaries are compared with measurements of these steroids in aqueous extracts of the perfused ovaries.

\section{Materials and Methods}

Animal preparation. Wistar rats were bred in our own animal facility and housed under a 14-h daily light cycle which began at 07:00 h. The young females for the experiments were weaned when they reached a body weight of $60-65 \mathrm{~g}(\mathrm{at}$ $\sim 26$ days of age). At 09:00 $\mathrm{h}$ on the day after weaning, the rats were injected s.c. with 20 i.u. PMSG (G-4877, Sigma Chemical Co., St Louis, MO, USA). Approximately $48 \mathrm{~h}$ later, the animals were anaesthetized i.p. with $90 \mathrm{mg}$ ketamine/kg body weight (Ketaset: Bristol Laboratories, Syracuse, NY, USA). Then 200 i.u. heparin sodium salt/rat (H-700, Sigma) were injected i.v. via a tail vein.

Ovary extirpation. The ovaries were removed by a procedure which has been described elsewhere (Koos et al., 1984). In brief, all vessels connecting to the descending aorta and posterior vena cava between the hepatic vessels 
anteriorly and the femoral branches posteriorly were ligated and severed, except for those circulating the right ovary. Next, in rapid sequence, the aorta and vena cava were cannulated in a cranial direction at a point just anterior to the femoral bifurcation, and then these vessels were ligated anteriorly and posteriorly to the dissection. The right ovary and its vascular connections to the cannulas were quickly dissected free from the mesovarian ligaments. The extirpated ovaries were initially perfused with warm $\left(37^{\circ} \mathrm{C}\right) 0.15 \mathrm{M}-\mathrm{NaCl}$ solution to flush the blood from the vessels and to check for any leakage at the vascular ligatures. Subsequently, the ovaries were transferred to the perfusion chamber, and the arterial cannula was attached to a male Luer connection which delivered oxygenated medium to the chamber. The arterial cannulas were 20-gauge (QUIK-CATH, Travenol Laboratories, Inc., Deerfield, IL, USA) and the venous cannulas were 18-gauge (QUIK-CATH, Travenol).

Perfusion procedure. Every effort was made to duplicate the procedure that has been used in other laboratories (Janson et al., 1982; Koos et al., 1984; Brännström et al., 1987a). Perfusions were performed at $38^{\circ} \mathrm{C}$ in a recirculating perfusion system (purchased from the Department of Physiology, University of Goteborg, Goteborg, Sweden) which has been described in detail elsewhere (Janson et al., 1982; Brännström et al., 1987a). The basic components of the system were a perfusion chamber, an oxygenator/reservoir, a bubble trap, and an humidifier (Fig. 1). Siliconization of these components and the tubing which connected them together was accomplished by immersing them in Sigmacote (SL-2, Sigma) for $1 \mathrm{~min}$. The perfusion medium consisted of $70 \mathrm{ml} \mathrm{M}-199$ containing Earle's salt and L-glutamine (320-1150AJ, GIBCO Laboratories, Grand Island, NY, USA). This medium was supplemented with a mixture of penicillin, streptomycin, and amphotericin B (A9909, Sigma) diluted to a final concentration of $100 \mathrm{U} / \mathrm{ml}, 100 \mu \mathrm{g} / \mathrm{ml}$, and $250 \mathrm{ng} / \mathrm{ml}$, respectively. In addition, heparin sodium salt (H7005, Sigma), insulin (I5500, Sigma), and bovine serum albumin (BSA; fatty acid-free fraction V; Boehringer-Mannheim Biochemicals, Indianapolis, IN, USA) were added to the medium in final amounts of $0.2 \mathrm{IU} / \mathrm{ml}, 0.02 \mathrm{IU} / \mathrm{ml}$, and $40 \mathrm{mg} / \mathrm{ml}$, respectively. The recirculating medium was exposed to an humidified mixture of $95 \% \mathrm{O}_{2}$ and $5 \% \mathrm{CO}_{2}$. The perfusion pressure was maintained between 60 and $90 \mathrm{mmHg}$ to produce an average ovarian flow rate of $0.6-0.8 \mathrm{ml} / \mathrm{min}$. After an ovary had been perfused for $1 \mathrm{~h}$, the ovulatory process was initiated by adding ovine luteinizing hormone (oLH; NIADDK-oLH-25, courtesy of the NIADDK, Bethesda, MD, USA) at $100 \mathrm{ng} / \mathrm{ml}$ to the oxygenator/reservoir of the perfusion system. This procedure resulted in an ovulation rate of $8.5 \pm 1.4$ ova/ovary in a group of 8 control ovaries that were perfused for $22-24 \mathrm{~h}$. Ova were counted by removing the subovarian vessel from the perfusion chamber and examining its content with a dissecting microscope.

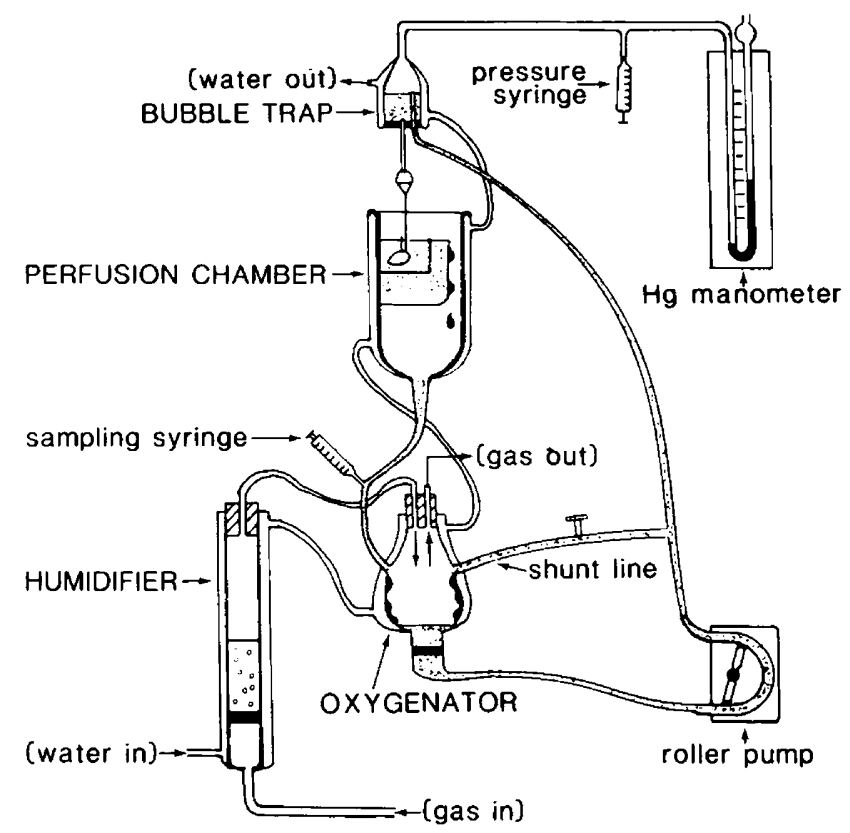

Fig. 1. Basic components of the perfusion system.

Perfusion fluid sampling. At $0,1,2,4,8$ and $12 \mathrm{~h}$ after $\mathrm{LH}$ administration, a $1.0 \mathrm{ml}$ sample of perfusion fluid was withdrawn from the tubing which returned the medium from the perfusion chamber to the oxygenator/reservoir. Immediately after the withdrawal, an equivalent amount of fresh medium was added to the oxygenator/reservoir.

Ovary extraction. Ovaries were also removed from the perfusion chamber at $0,1,2,4,8$ and $12 \mathrm{~h}$ after $\mathrm{LH}$ administration and placed in $1.0 \mathrm{ml} \mathrm{M-199}$ in a glass/glass homogenizer ( $\mathrm{S} 62$ pestle and S73 tube, Tri-R Instruments, 
Inc., Rockville Center, NY, USA) connected to a stirrer (S63, Tri-R). The ovaries were homogenized for 30 sec at medium speed ( $\sim 5000 \mathrm{rev} / \mathrm{min})$. The homogenates were centrifuged at $10000 \mathrm{~g}$ for $20 \mathrm{~min}$, and the supernatant fluids were transferred to a polyethylene tube, capped, and stored at $-20^{\circ} \mathrm{C}$ until a complete series of experimental samples could be assayed simultaneously.

Design of the steroid secretion experiments. The three steroids were measured in two different types of experiments. In the first study, 42 ovaries were perfused. Seven ovaries each were removed (for extraction and later assay) after $1 \mathrm{~h}$ of equilibration (i.e. at $0 \mathrm{~h}$ after $\mathrm{LH}$ ) and at 1, 2, 4, 8 and $12 \mathrm{~h}$ after $\mathrm{LH}$ administration. A corresponding sample of perfusion fluid was withdrawn from the system within 1 min before removal of each ovary. These samples were designated as 'perfusion fluid A'. Thus the steroids in perfusion fluid A were secreted from the same ovaries that were removed at different times after LH administration. In the second experiment, 7 ovaries were perfused for the full 12-h duration of the experiment, and the circulating medium was sampled at each of the given intervals following $\mathbf{L H}$ administration. These samples were designated as 'perfusion fluid B'. (This latter protocol has been the common method in the past.) Since the same ovary was monitored for the duration of the experiment, this procedure has the advantage of providing a relatively accurate indication of the temporal changes in the steroids in the perfusion fluid. However, the continuous perfusion makes it impossible to remove ovaries during the earlier stages of the ovulatory process and determine whether the steroid concentrations in the perfusion fluid accurately reflect the steroid values in the ovaries. The first experiment was designed to make this assessment.

Estimation of steroid adsorption by the perfusion system. The three steroids were dissolved together in $1.0 \mathrm{ml} 100 \%$ ethanol and added to $69 \mathrm{ml}$ perfusion fluid in a polyethylene beaker to a final concentration of $100 \mathrm{ng}$ each steroid/ml medium. After $1 \mathrm{~min}$ of vigorous stirring a $1 \cdot 0-\mathrm{ml}$ sample was withdrawn to serve as the 0 -h control sample. The remaining $69 \mathrm{ml}$ medium were placed immediately in the perfusion system and circulated at the normal flow rate. At 1 , 2,4 and $8 \mathrm{~h}$ later, $1 \cdot 0 \mathrm{ml}$ samples of the perfusion fluid were withdrawn to determine the rate at which the steroids were adsorbed by the walls of the system.

Tubing. Tygon R3603 (14-169-1E, Fisher Scientific Co., Pittsburgh, PA, USA) was used for the roller pump tubing. Viton (J6434-02 and J6434-03, Cole-Parmer Instrument Co., Chicago, IL, USA) and Teflon (J6407-44, ColeParmer) were used to connect the different glass components of the system together. In one circulation, the perfusion fluid was exposed to $350 \mathrm{~mm}$ Tygon tubing, $560 \mathrm{~mm}$ Viton tubing, and $320 \mathrm{~mm}$ Teflon tubing.

Steroid radioimmunoassays. The steroids were assayed at the Centre for Research in Reproductive Biology in the Department of Obstetrics and Gynecology at The University of Texas Health Science Center in San Antonio. The radioimmunoassays were performed by the same procedure that has been described previously for progesterone and oestradiol (Siler-Khodr et al., 1984). The minimum sensitivity of the progesterone assay was $2565 \mathrm{pg} / \mathrm{tube}$, and it had a cross-reactivity of $3.3 \%$ with deoxycorticosterone and $\leqslant 1.0 \%$ with other common steroids. The minimum sensitivity of the testosterone assay was $1265 \mathrm{pg} /$ tube, and it had a cross-reactivity of $28.0 \%$ with 19 -hydroxytestosterone, $7 \cdot 0 \%$ with $5 \alpha$-dihydrotestosterone, $2 \cdot 2 \%$ with $5 \alpha$-androstane- $3 \beta, 17 \beta$-diol, $2 \cdot 0 \%$ with 11 -oxotestosterone, and $\leqslant 1 \cdot 0 \%$ with other steroids. The minimum sensitivity of the oestradiol- $17 \beta$ assay was $1285 \mathrm{pg} / \mathrm{tube}$, and it had a crossreactivity of $2 \cdot 5 \%$ with oestriol, $1 \cdot 3 \%$ with oestradiol- $17 \alpha, 1 \cdot 3 \%$ with oestrone, and $\leqslant 1.0 \%$ with other steroids. The intra-assay coefficients of variation for the progesterone, testosterone and oestradiol-17 $\beta$ assays were $6.3 \%, 8.6 \%$, and $7 \cdot 5 \%$, respectively, and the inter-assay coefficients of variation were $6.4 \%, 3 \cdot 8 \%$, and $8.6 \%$, respectively.

Statistical analysis. The results are expressed as means \pm s.e.m. The significances of the differences between means at different intervals over the course of the $12 \mathrm{~h}$ were determined by Duncan's Multiple Range Test. The significances of the correlations in the steroid concentrations in the different sources of samples were determined by Pearson's Product-Moment Correlation. The level of significance was taken as $P \leqslant 0.05$.

\section{Results}

\section{Steroid adsorption by the perfusion system}

Progesterone exhibited the greatest adsorption by the inner walls of the perfusion system. When $100 \mathrm{ng}$ of this steroid was added per $\mathrm{ml} \mathrm{M}-199,66 \%$ was adsorbed during the first hour of circulation through the system (Fig. 2). Without 4\% BSA added to the medium, $90 \%$ of the progesterone was adsorbed during the first hour. By the end of the $8-\mathrm{h}$ test, $95 \%$ and $96 \%$ were adsorbed from the media with and without BSA, respectively. Only $33 \%$ of the testosterone was adsorbed during the first hour, and this increased slightly to $41 \%$ in the absence of BSA (Fig. 2). After $8 \mathrm{~h}$, $52 \%$ and $73 \%$ were adsorbed from the media with and without BSA, respectively. During the first hour, there was negligible adsorption of oestradiol if BSA was added to the medium, but $32 \%$ was adsorbed in the absence of BSA (Fig. 2). After $8 \mathrm{~h}$, there still was no adsorption of oestradiol when BSA was in the medium, but $75 \%$ of this steroid was adsorbed in the absence of BSA. 


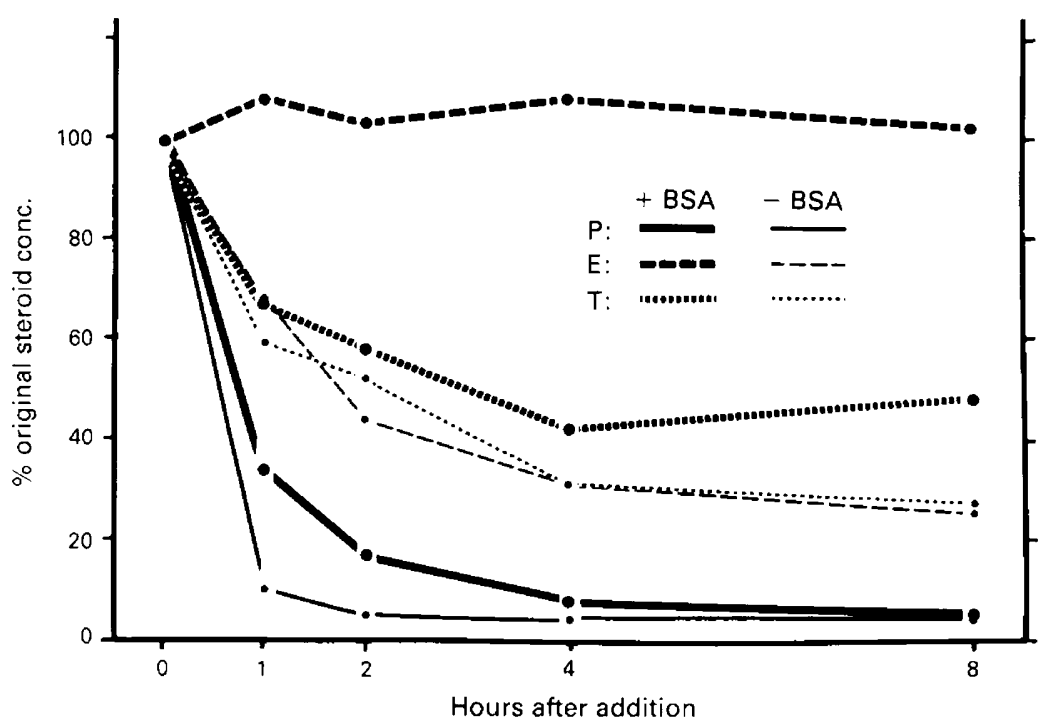

Fig. 2. Rate of adsorption of progesterone (P), testosterone (T), and oestradiol (E) to the walls of the perfusion system when bovine serum albumin (BSA) was, or was not, added to the perfusion fluid. The initial concentration of each of the three steroids was $100 \mathrm{ng} / \mathrm{ml}$ fluid. Values are means of duplicates.

\section{Progesterone secretion}

Progesterone increased significantly $(P<0.01)$ in Perfusion fluids A and B within $2 \mathrm{~h}$ after $\mathrm{LH}$ administration, but the amount of this steroid within the ovaries did not increase significantly $(P<0.05)$ until $4 \mathrm{~h}$ after LH (Fig. 3a). After $4 \mathrm{~h}$, the amount of progesterone in the ovaries and in the perfusion fluids declined steadily. During the $12 \mathrm{~h}$ period after LH administration, there was a significant correlation $(P<0.05)$ between the measurements of progesterone in the ovaries and in Perfusion fluid $\mathrm{A}$, but there was not a significant correlation $(P>0 \cdot 20)$ between the ovaries and Perfusion fluid B. However, there was a significant correlation $(P<0.05)$ in the concentrations of progesterone in the two types of perfusion fluid.

\section{Testosterone secretion}

Testosterone increased significantly $(P<0.01)$ in the ovarian extract within $1 \mathrm{~h}$ after $\mathrm{LH}$ administration, and there was about 4 times as much in the extracts compared to the fluids (Fig. 3b). Although this steroid decreased $(P<0.05)$ in the ovarian extracts between 1 and $2 \mathrm{~h}$ after $\mathrm{LH}$, it did not increase significantly $(P<0.05)$ in the two perfusion fluids until $2 \mathrm{~h}$ after LH. During the 12-h perfusion period, there was not a significant correlation $(P>0.80)$ between the amount of testosterone in the ovaries compared to either type of perfusion fluid. However, there was a correlation $(P<0.01)$ in the concentrations of this steroid in the two perfusion fluids.

\section{Oestradiol secretion}

Like testosterone, oestradiol increased $(P<0.05)$ in the samples of ovarian extracts within the first hour after LH administration, but did not increase significantly $(P<0.05)$ in either of the perfusion fluids until $4 \mathrm{~h}$ after $\mathrm{LH}$, at a time when the amount in the ovarian extracts was declining $(P<0.05)$ (Fig. 3c). Also, there was not a significant correlation $(P<0.30)$ between the concentration of oestradiol in the ovaries compared to either type of perfusion fluid, while there was a correlation $(P<0.01)$ in the amounts in the two perfusion fluids. 

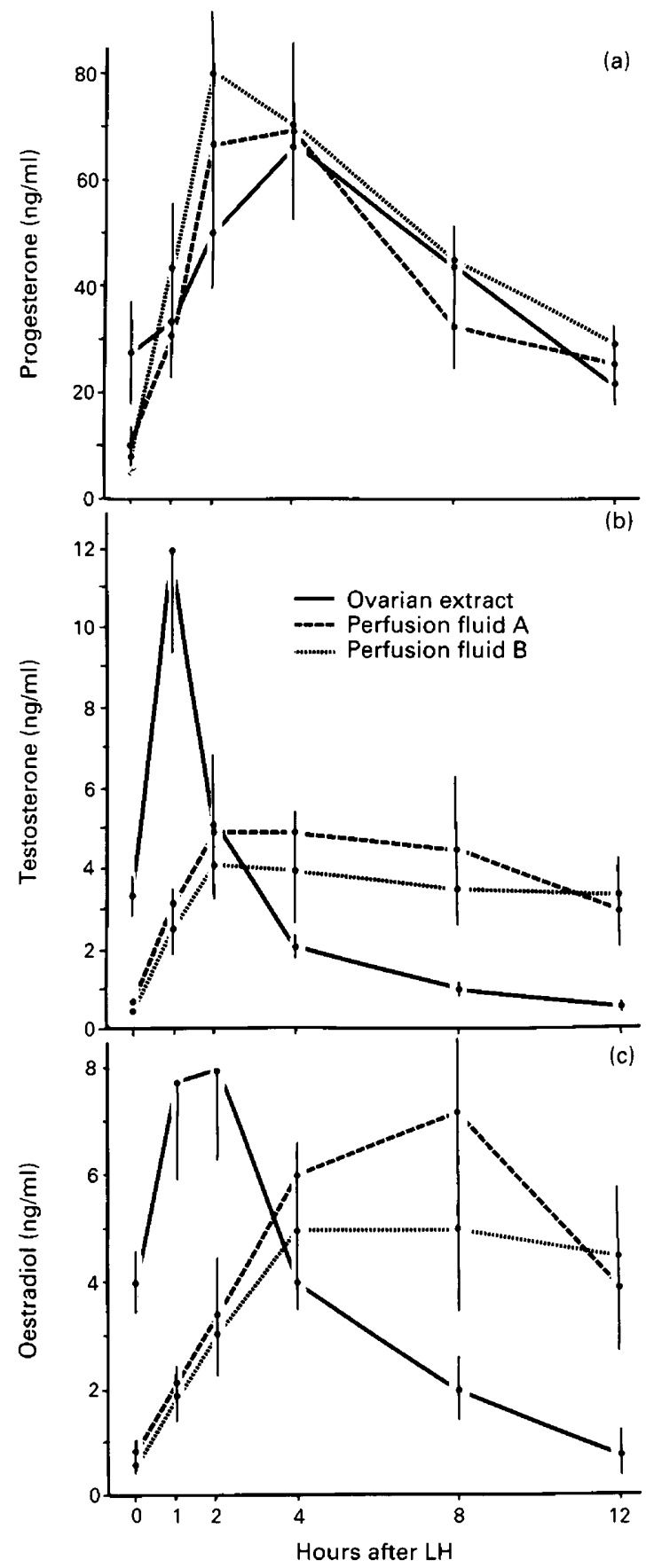

Fig. 3. Comparison of the concentrations of (a) progesterone, (b) testosterone and (c) oestradiol- $17 \beta$ in the ovary and in the two types of perfusion fluid after LH stimulation of the ovulatory process. Values are means \pm s.e.m. for 7 ovaries per mean. 


\section{Discussion}

Although the progesterone pattern in the perfusion fluid tended to follow the concentration of this steroid in ovarian extracts, the profound differences in the profiles of testosterone and oestradiol make it clear that the steroid values in the perfusion fluid are not an accurate reflection of the steroidogenic activity in the ovary. There are at least two possible reasons for this discrepancy. First, as in other studies, the total volume of the perfusion fluid in the system was $70 \mathrm{ml}$. Such a large reservoir dilutes the ovarian secretions and diminishes any measurable changes in the steroids when the samples are taken from the fluid. The second problem is with the inner walls of the perfusion system, and, in particular, with the tubing which connects the glass components of the system together. The plastic tubing commonly used in laboratories adsorbs steroid hormones (Westphal et al., 1975; Bruning et al., 1981). In the order of greatest adsorption, silicone rubber, Tygon, Viton, and to a lesser extent Teflon adsorb the less polar steroids. This problem has been recognized for progesterone in the ovarian perfusion system (Janson et al., 1982; Brännström et al., $1987 \mathrm{a})$. The present results reveal that testosterone and oestradiol are also adsorbed, unless BSA is added to the medium. Non-specific binding of the steroids to albumin makes them considerably less vulnerable to adsorption by plastic tubing (Westphal et al., 1975; Bruning et al., 1981; Westphal, 1985). The fact that the progesterone profile in the fluid happened to be closer to its profile in the ovarian extracts may therefore be, in part, the consequence of its secretion rate, its binding to BSA, and its adsorption by the walls of the tubing of the perfusion system.

In gonadotropin-treated immature rats, concentrations of progesterone, testosterone and oestradiol in the follicular fluid all increase within $1 \mathrm{~h}$ after $\mathrm{LH}$ treatment (Goff \& Henderson, 1979). The progesterone concentration remains elevated for at least $10 \mathrm{~h}$, but testosterone and oestradiol decline to below 0 -h control levels within $6 \mathrm{~h}$ after $\mathrm{LH}$. These findings are similar to those obtained with extracts from rat ovaries in vivo (unpublished observations) and in the present extracts from in-vitro perfused ovaries. Likewise, in-vivo studies of rabbit ovarian follicles (Patwardhan \& Lanthier, 1976) and of ovarian venous output (Wu et al., 1977; Bahr, 1978) reveal a comparable steroid profile following gonadotrophic stimulation of the ovulatory process. However, the concentrations of progesterone, testosterone and oestradiol in the peripheral blood are substantially less (Wu et al., 1977), and their secretion profile resembles the pattern in the perfusion fluid in the present study. These steroid profiles in the perfusion fluid are similar to those of other perfusion studies with the rat ovary (Koos et al., 1984; Koos \& LeMaire, 1985; Shaykh et al., 1985; Brännström et al., 1987a, b) and of the rabbit ovary (Janson et al., 1982; Koos et al., 1983; Holmes et al., 1983, 1985, 1986; Schmidt et al., 1986; Yoshimura et al., 1986, 1987).

In this study, the control ovulation rate of $8.5 \pm 1.4$ ova/ovary is in the range of the rate reported by others who have used the in-vitro perfusion procedure (Koos et al., 1984; Brännström et al., 1987a), and this in itself is evidence that our methodology was comparable to theirs. However, this relatively moderate ovulation rate is a cause for additional concern about the value of the in-vitro perfusion method because the rate in vivo in gonadotrophin-primed immature rats is closer to 30 ova/ovary (Espey et al., 1989). It therefore appears that there may be other deficiencies in the perfusion method that need to be resolved. Although the in-vitro ovulation rate can be doubled by adding the phosphodiesterase inhibitor isobutylmethylzanthine to the perfusion fluid (Brännström et al., 1989; unpublished observation), this artificial rate is still only about one-half of the rate in vivo. A number of conditions could be responsible for this lower rate in vitro. Besides the surgical trauma to the excised ovaries, the perfusion medium may be an inadequate substitute for whole blood. Higher ovulation rates might be achieved by conducting tests to determine the optimal concentrations of gases, gonadotrophins, BSA, antibiotics, insulin, and other substances such as steroids and eicosanoids within the perfusion fluid. However, a thorough analysis of all of the variables would be an enormous task that is beyond the scope of the present study.

The present results demonstrate that the steroid concentrations in the fluid of perfusion systems may not accurately reflect the steroidogenic activity in perfused ovaries. Therefore, if this method is 
to be applied to studies of the metabolic events within the ovary, then the assay of ovarian extracts, rather than perfusion fluids, may provide a more realistic indication of the biochemical changes which contribute to ovulation.

We thank Dr William J. LeMaire and Dr Per O. Janson for their comments on a preliminary draft of this paper; and Julie Forman for the steroid radioimmunoassays. This work was supported by NIH Grants HD-21649 and P30-HD-10202.

\section{References}

Bahr, J.M. (1978) Simultaneous measurements of steroids in follicular fluid and ovarian venous blood in the rabbit. Biol. Reprod. 18, 193-197.

Brännström, M., Johansson, B.M., Sogn, J. \& Janson, P.O. (1987a) Characterization of an in vitro perfused rat ovary model: ovulation rate, oocyte maturation, steroidogenesis and influence of PMSG priming. Acta physiol. scand. 130, 107-1 14.

Brännström, M., Koos, R.D., LeMaire, W.J. \& Janson, P.O. (1987b) Cyclic adenosine 3',5'-monophosphateinduced ovulation in the perfused rat ovary and its mediation by prostaglandins. Biol. Reprod. 37, 1047-1053.

Brännström, M., Boberg, B.M., Törnell, J., Janson, P.O. \& Ahrén, K. (1989) Effects of inhibitors of protein synthesis on the ovulatory process of the perfused rat ovary. J. Reprod. Fert. 85, 451-459.

Bruning, P.F., Jonker, K.M. \& Boerema-Baan, A.W. (1981) Adsorption of steroid hormones by plastic tubing. J. Steroid Biochem. 14, 553-555.

Espey, L.L., Tanaka, N. \& Okamura, H. (1989) Increase in ovarian leukotrienes during hormonally induced ovulation in the rat. Am. J. Physiol. 256, E753-E759.

Goff, A.K. \& Henderson, K.M. (1979) Changes in follicular fluid and serum concentrations of steroids in PMS treated immature rats following $\mathrm{LH}$ administration. Biol. Reprod. 20, 1153-1157.

Holmes, P.V., Janson, P.O., Sogn, J., Källfelt, B., LeMaire, W.J., Ahrén, K.B., Cajander, S. \& Bjersing, L. (1983) Effects of PGF Pa $_{2}$ and indomethacin on ovulation and steroid production in the isolated perfused rabbit ovary. Acta endocr., Copenh. 104, 233-239.

Holmes, P.V., Sogn, J., Schillinger, E. \& Janson, P.O. (1985) Effects of high and low preovulatory concentrations of progesterone on ovulation from the isolated perfused rabbit ovary. J. Reprod. Fert. 75, 393-399.

Holmes, P.V., Hedin, L. \& Janson, P.O. (1986) The role of cyclic adenosine $3^{\prime}, 5^{\prime}$-monophosphate in the ovulatory process of the in vitro perfused rabbit ovary. Endocrinology 118, 2195-2202.

Janson, P.O., LeMaire, W.J., Källfelt, B., Holmes, P.V., Cajander, S., Bjersing, L., Wiquist, N. \& Ahrén, K. (1982) The study of ovulation in the isolated perfused rabbit ovary. I. Methodology and pattern of steroidogenesis. Biol. Reprod. 26, 456-465.

Koos, R.D. \& LeMaire, W.J. (1985) The effects of a gonadotropin-releasing hormone agonist on ovulation and steroidogenesis during perfusion of rabbit and rat ovaries in vitro. Endocrinology 116, 628-632.

Koos, R.D., Clark, M.R., Janson, P.O., Ahrén, K.E.B. \&
LeMaire, W.J. (1983) Prostaglandin levels in preovulatory follicles from rabbit ovaries perfused in vitro. Prostaglandins 25, 715-724.

Koos, R.D., Jaccarino, F.J., Magaril, R.A. \& LeMaire, W.J. (1984) Perfusion of the rat ovary in vitro: methodology, induction of ovulation and pattern of steroidogenesis. Biol. Reprod. 30, 1135-1141.

LeMaire, W.J., Janson, P.O., Källfelt, B.J., Holmes, P.V., Cajander, S., Bjersing, L. \& Ahrén, K.E.B. (1982) The preovulatory decline in follicular oestradiol is not required for ovulation in the rabbit. Acta endocr., Copenh. 101, 452-457.

Patwardhan, V.V. \& Lanthier, A. (1976) Effect of an ovulatory dose of luteinizing hormone on the concentration of oestrone, oestradiol and progesterone in the rabbit ovarian follicles. Acta endocr., Copenh. 82, $792-800$.

Schmidt, G., Holmes, P.V., Owman, Ch., Sjoberg, N.O. \& Walles, B. (1986) The influence of prostaglandin $E_{2}$ and indomethacin on progesterone production and ovulation in the rabbit ovary perfused in vitro. Biol. Reprod. 35, 815-821.

Shaykh, M., LeMaire, W.J., Papkoff, H., Curry, T.E., Jr, Sogn, J.H. \& Koos, R.D. (1985) Ovulations in rat ovaries perfused in vitro with follicle-stimulating hormone. Biol. Reprod. 33, 629-636.

Siler-Khodr, T., Keuhl, T.J. \& Vickery, B.H. (1984) Effects of a gonadotropin releasing hormone antagonist on hormonal levels in the pregnant baboon and on fetal outcome. Fert. Steril. 41, 448-453.

Thibault, C. \& Levasseur, M.C. (1988) Ovulation. Hum. Reprod. 3, 513-523.

Wallach, E.E., Wright, K.H. \& Hamada, Y. (1978) Investigation of mammalian ovulation with an in vitro perfused rabbit ovary preparation. $A m$. J. Obstet. Gynecol. 132, 728-738.

Westphal, U. (1985) Steroid-Protein Interactions II. Springer-Verlag, New York.

Westphal, U., Burton, R.M. \& Harding, G.B. (1975) Characterization of steroid-binding glycoproteins: Methodological comments. Methods Enzymol. 36, 91-104.

Wu, C.H., Blasco, L., Flickinger, G.L. \& Mikhail, G. (1977) Ovarian function in the preovulatory rabbit. Biol. Reprod. 17, 304-308.

Yoshimura, Y., Hosoi, Y., Atlas, S.J., Bongiovanni, A.M., Santulli, R. \& Wallach, E.E. (1986) The effect of ovarian steroidogenesis on ovulation and fertilizability in the in vitro perfused rabbit ovary. Biol. Reprod. 35, 943-948. 
Yoshimura, Y., Hosoi, Y., Bongiovanni, A.M., Santulli, R., Atlas, S.J. \& Wallach, E.E. (1987) Are ovarian steroids required for ovum maturation and fertilization? Effects of cyanoketone on the in vitro perfused rabbit ovary. Endocrinology 120, 2555-2561.
Yoshimura, Y., Espey. L., Hosoi, Y., Adachi, T., Atlas, S.J., Ghodgaonkar, R.B., Dubin, N.H. \& Wallach, E.E. (1988) The effects of bradykinin on ovulation and prostaglandin production by the perfused rabbit ovary. Endocrinology 122, 2540-2546.

Received 17 May 1989 